\title{
Surface-Assisted Reduction of Aniline Oligomers, $N$-Phenyl-1,4-Phenylenediimine and Thionin in Atmospheric Pressure Chemical Ionization and Atmospheric Pressure Photoionization
}

\author{
Vilmos Kertesz* and Gary J. Van Berkel \\ Organic and Biological Mass Spectrometry Group, Chemical Sciences Division, Oak Ridge National Laboratory, \\ Oak Ridge, Tennessee, USA
}

\begin{abstract}
Reduction of the oligomers formed from on-line electropolymerization of aniline, the compound N-phenyl-1,4-phenylenediimine, and the thiazine dye thionin was observed in both an atmospheric pressure chemical ionization and an atmospheric pressure photoionization source. The reduction, which alters the mass of these analytes by $2 \mathrm{Da}$, was shown to occur by means of a surface-assisted process which involves reactive species, possibly hydrogen radicals, generated from protic solvents in the ionization plasma. Reduction was minimized by limiting protic solvents, by using a high heated nebulizer temperature, and by using a clean, heated nebulizer probe liner. The expected generality of this reduction process, and the possibility of similar reduction processes in other plasma ionization sources are discussed in relation to the use of these ion sources for on-line electrochemistry/mass spectrometry experiments. (J Am Soc Mass Spectrom 2002, 13, 109-117) Published by Elsevier Science Inc.
\end{abstract}

I a recent report, Karancsi and Slégel [1] showed that aromatic nitro compounds are reduced to the corresponding amines in an atmospheric pressure chemical ionization source (APCI) [2]. The extent of reduction, from a few percent to complete reduction, was found to be dependent on the compound and on the nature of the solvent system. Reduction was promoted with protic solvents like water and methanol, but diminished or eliminated in dried acetonitrile or methylene chloride. The occurrence of this reduction (assumed to occur in the gas-phase) was likened to that observed for aromatic nitro compounds in a traditional chemical ionization (CI) source [3], but no details of the possible mechanisms were discussed. Reductions and other secondary processes in CI [3] and other ionization sources in which a reactive plasma can form, such as electron ionization (EI) [4], secondary ion mass spectrometry (SIMS) [5], thermospray (TS) [6], and particle

Published online November 30, 2001

Address reprint requests to Dr. G. J. Van Berkel, Chemical Sciences Division, Oak Ridge Laboratory, Oak Ridge, TN 37831-6365, USA. E-mail: vanberkelgj@ornl.gov

This manuscript has been authored by a contractor of the U.S. Government under contract DE-AC05-00OR22725.

* Current address: Györ, Móra Ferenc tér 14. I/3, H-9028, Hungary. E-mail: macasoft@matavnet.hu

beam (PB) [7], are well documented. Karancsi and Slégel [1] are, however, apparently the first and only group to report analyte reduction in APCI, suggesting that this is a rare phenomenon with this ionization source.

Our concern with the possibility of such reduction processes lies in the use of APCI, or the new related technique, atmospheric pressure photoionization (APPI) [8], as an interface for on-line electrochemistry mass spectrometry (EC/MS) experiments [9]. In recent years, electrospray (ES) has proven to be very suitable for EC/MS [10-25], supplanting TS as the ionization interface of choice. Relatively nonrestrictive operational parameters have been identified that ensure that the inherent electrochemical process of ES will not alter the products of the electrochemistry which occurs in the on-line cell [26]. Thus, the ions observed in the gasphase using ES-MS appear to be an accurate reflection of those species present in the solution exiting the electrochemical cell. Nonetheless, the use of APCI (or APPI) for EC/MS experiments would expand the range of compounds amenable to study beyond those suitable to ES-MS (e.g., nonpolar analytes). It would also provide, in general, added experimental flexibility (e.g., different variations in solvents, additives, and flow rates). However, reduction processes in the ion source that alter the distribution of the species originally 
introduced from an electrochemical cell into the source are undesirable. Of particular significance is the fact that the APCI reduction reported by Karancsi and Slégel (nitro groups to amines) [1] is equivalent to the electrochemical reaction for this functional group [27].

During the course of investigating APCI and APPI for the study of electrochemical formation of conductive polymers, we found that several of the species of interest were reduced in these ion sources. In this paper, we report on the APCI and APPI reduction of the oligomers formed from on-line electropolymerization of aniline, the compound $\mathrm{N}$-phenyl-1,4-phenylenediimine (the equivalent of the electrochemically formed aniline dimer), and the thiazine dye thionin. Each of these species can be reversibly converted electrochemically between their initial oxidized states and their reduced states by a nominal two-proton, two-electron process $[17,26,28]$. The reduction products formed electrochemically are the same as those we observe in the APCI and APPI ion sources. To elucidate the mechanism of the reduction, we compare the ES mass spectra of these compounds with the APCI mass spectra (and in some cases with the APPI mass spectra) obtained as a function of (1) heated nebulizer probe temperature, (2) heated nebulizer cleanliness, (3) APCI corona discharge current, and (4) the solvent system. Means to minimize the extent of reduction, the expected generality of the reduction process, and the possibility of similar reduction processes in other plasma ionization sources are discussed.

\section{Experimental}

All mass spectra were acquired using either an API165 single quadrupole or API365 triple quadrupole mass spectrometer (SCIEX, Concord, Ontario, Canada) equipped with interchangeable ES, APCI, and APPI sources. In the TurbolonSpray ES ion source, a $30 \mathrm{~cm}$ long, PEEK transfer tube $(60 \mu \mathrm{m}$ i.d., Upchurch Scientific, Oak Harbor, WA) connected a $3.5 \mathrm{~cm}$ long metal ES capillary emitter to the stainless steel $254 \mu \mathrm{m}$ i.d. bore-through bulkhead grounding union built into the TurboIonSpray source assembly. The atmospheric sampling interface orifice and ring electrode voltages were set to maximize analyte signal and minimize fragmentation. The voltage applied to the stainless steel capillary emitter $(400 \mu \mathrm{m}$ o.d. and $100 \mu \mathrm{m}$ i.d., SCIEX) was $4.5 \mathrm{kV}$. The emitter was placed $1.5 \mathrm{~cm}$ from the $\mathrm{N}_{2}$ curtain gas plate aperture (held at $1.0 \mathrm{kV}$ ), and angled to spray across the aperture. Nitrogen was used for sample nebulization. No "Turbo" gas was used.

The corona discharge APCI source was used without modification. Nitrogen was used as the auxiliary and nebulizer gas. The quartz tube lining the heated nebulizer probe was cleaned by sonication in polar and nonpolar solvents followed by treatment with aqua regia and further sonication in the various solvents. Corona discharge current was varied from $0-5 \mu \mathrm{A}$ for various experiments.
Details of the prototype APPI source are the same as those presented elsewhere [8]. This source makes use of the same heated nebulizer probe as used in the APCI experiments. A vacuum-ultraviolet lamp providing 10 $\mathrm{eV}$ photons is used rather than a corona discharge to initiate an ion-molecule reaction cascade producing reagent ions. Distilled acetone (Baker, Phillipsburg, NJ), which is photoionizable, was added as a dopant (10 $\mu \mathrm{L} / \mathrm{min}$ ) with the auxiliary gas (nitrogen) to initiate the formation of the reagent ions [8].

Sample solutions were prepared using acetonitrile (Burdick \& Jackson, Muskegon, MI), methanol (Burdick \& Jackson), and water (Milli-RO 12 Plus, Millipore, Bedford, MA). Stock solutions of aniline, N-phenyl-1,4phenylenediamine, and thionin (all from Aldrich, Milwaukee, WI) were prepared in water or methanol. Aniline was distilled just prior to preparing and analyzing the sample solutions. Ammonium acetate (Aldrich, $5.0 \mathrm{mM}$ ) and acetic acid were added to sample solutions to achieve $\mathrm{pH} 4$. Formic acid was added to solutions to achieve $\mathrm{pH} 3$. Analyte sample solutions were either continuously infused or flow injected (Rheodyne 7125 injector, Cotati, CA) into the respective ion sources using either a Harvard Apparatus 22 syringe pump (Southnatick, MA) or an ABI 140B dual syringe solvent delivery system (Foster City, CA) at flow rates ranging from 10 to $200 \mu \mathrm{L} / \mathrm{min}$. Aniline was electropolymerized on-line in a thin layer flow-by electrode electrochemical cell using a $6.0 \mathrm{~mm}$ diameter glassy carbon working electrode disk $(1.0 \mathrm{~V})$, platinum counter electrode, and $\mathrm{Ag} / \mathrm{AgCl}$ reference electrode. Details of the electrochemical cell are provided elsewhere $[17,18]$. The same cell and conditions were used to oxidize $N$-phenyl-1,4-phenylenediamine on-line to $\mathrm{N}$-phenyl-1,4-phenylenediimine.

\section{Results and Discussion}

All ES, APCI, and APPI data shown below were acquired at a solvent flow rate of $50 \mu \mathrm{L} / \mathrm{min}$. This is the maximum flow rate at which our electrochemical cell can be operated and still provide very high electrolysis efficiency [18]. In general, when the electrochemical cell was not required in experiments, similar mass spectral observations to those we report for $50 \mu \mathrm{L} / \mathrm{min}$ were obtained at both higher (up to $200 \mu \mathrm{L} / \mathrm{min}$ ) and lower (down to $10 \mu \mathrm{L} / \mathrm{min}$ ) flow rates. Furthermore, because all our APCI and APPI results were comparable and chemistry considerations in both sources are similar, the APCI results are emphasized in the discussion for clarity and brevity.

Figure 1a shows three $\mathrm{m} / \mathrm{z}$ segments of the on-line EC/ES-MS spectrum of aniline (aqueous methanol, $\mathrm{pH}$ 4) obtained at a working electrode potential of $1.0 \mathrm{~V}$. The peaks observed in these segments correspond to the protonated dimers (2-mers), trimers (3-mers), and tetramers (4-mers) of electropolymerized aniline [17]. These aniline oligomers are formed via a series of oxidation/addition reactions starting with the oxida- 

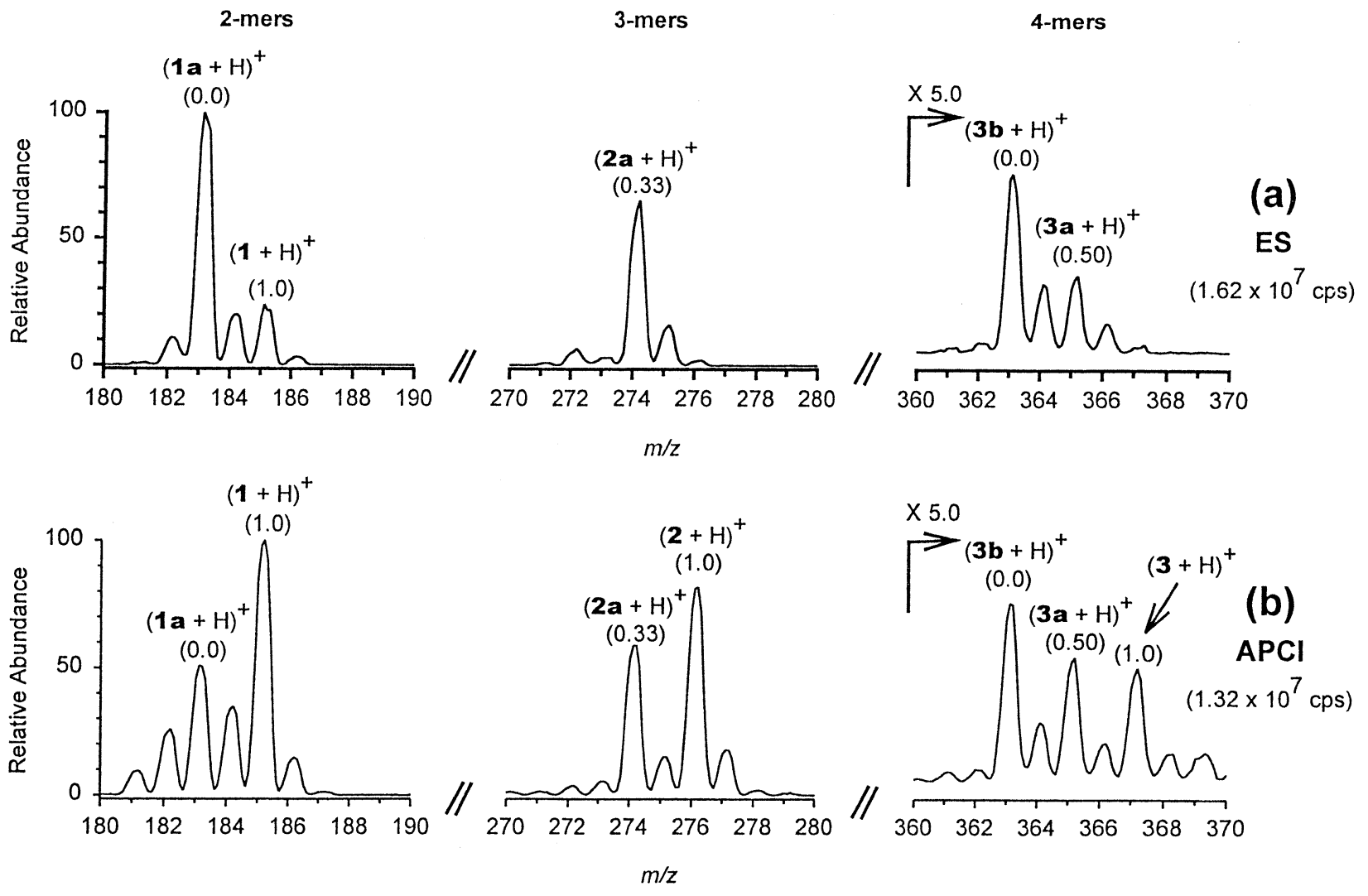

Figure 1. (a) EC/ES-MS and (b) EC/APCI-MS spectral segments showing the dimer (2-mer), trimer (3-mer), and tetramer (4-mer) products of the on-line electropolymerization of aniline. Aniline (100 $\mu \mathrm{M}$ in water/methanol [50/50 vol/vol] with $5.0 \mathrm{mM}$ ammonium acetate, $\mathrm{pH} 4$ ) was oxidized using a working electrode potential of $1.0 \mathrm{~V}$. For both ES and APCI the solvent flow rate was $50 \mu \mathrm{L} / \mathrm{min}$. For APCI the heated nebulizer temperature was $400{ }^{\circ} \mathrm{C}$ and the corona discharge current was $2 \mu \mathrm{A}$. Numbers in parentheses indicate the redox state of the oligomer $(0.0=$ fully oxidized; $1.0=$ fully reduced, see text).

tion of aniline to the radical cation followed by radicalradical coupling to form mainly the head-to-tail linked dimer (1). The dimers are in turn oxidized (1a) and grow to larger $n$-mers via addition of aniline to form the trimers $(\mathbf{2}, \mathbf{2} \mathbf{a})$ or the addition of another dimer molecule to form the tetramers $(\mathbf{3}, \mathbf{3} \mathbf{a}, \mathbf{3} \mathbf{b})$ and so on, by continued head-to-tail coupling [17].

This ES mass spectrum of electropolymerized aniline contained mainly the peaks corresponding to the protonated forms of the oxidized redox states of the aniline $n$-mers, viz., $(\mathbf{1} \mathbf{a}+\mathrm{H})^{+},(\mathbf{2} \mathbf{a}+\mathrm{H})^{+}$, and $(\mathbf{3} \mathbf{b}+\mathrm{H})^{+}$. Exceptions were the small abundance of fully reduced dimer at $\mathrm{m} / \mathrm{z}$ 185, $(\mathbf{1}+\mathrm{H})^{+}$, and the half-reduced tetramer at $m / z 365,(3 \mathbf{a}+\mathrm{H})^{+}$. (The redox state of an $n$-mer is defined as the ratio of the number of amine nitrogens to total (amine plus imine) nitrogens. Thus the redox states range in value from 1.0 for a fully reduced $n$-mer (all amine nitrogen) to 0.0 for a fully oxidized $n$-mer (all imine nitrogen)). This observation is consistent with the fact that the aniline dimers and higher $n$-mers are easier to oxidize than aniline [17]. At the electrode potential used to oxidize aniline and initiate the polymerization $(1.0 \mathrm{~V})$, the $n$-mers are oxidized.
The observed distribution of the redox states of these aniline oligomers was substantially different in the EC/APCI-MS spectrum as illustrated by the spectrum shown in Figure 1b. In this case, the fully reduced redox states were dominant for both the dimers $\left[(1+\mathrm{H})^{+}\right]$ and trimers $\left[(2+\mathrm{H})^{+}\right]$. The reduced tetramer $\left[(3+\mathrm{H})^{+}\right]$ was also observed at approximately $60 \%$ the intensity of the oxidized tetramer $\left[(3 \mathbf{b}+\mathrm{H})^{+}\right]$.

Because the electrochemistry and travel time from the cell to the mass spectrometer was nearly the same in both the EC/ES-MS and EC/APCI-MS experiments (a few seconds [18]), the differences among the spectra in Figures $1 \mathrm{a}$ and $\mathrm{b}$ must originate with the ion source. In fact, the differences we observed were consistent with a reduction in the APCI source of the oxidized $n$-mers produced in the electrochemical cell. To test this hypothesis, we used a commercially available sample of $\mathrm{N}$-phenyl-1,4-phenylenediamine, $\mathbf{1}$, the reduced form of the dimer formed by electropolymerization of aniline. Figure 2 presents the molecular ion region of the ES (Figure 2a), APCI (Figure 2b), and APPI (Figure 2c) mass spectra of a $\mathrm{pH} 4$ aqueous methanol solution of this compound. The base peak in the ES mass spectrum was observed at $\mathrm{m} / \mathrm{z} 185$, which corresponds to the 

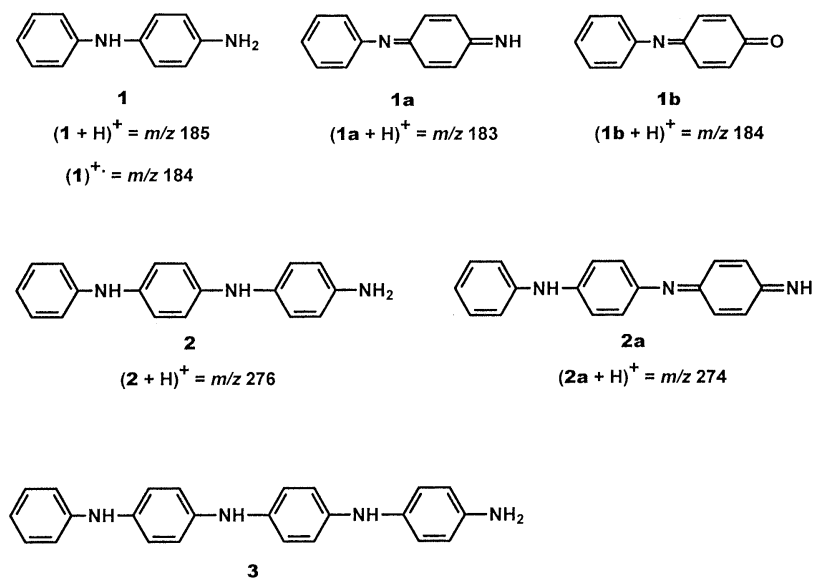

$(3+\mathrm{H})^{+}=m / z 367$

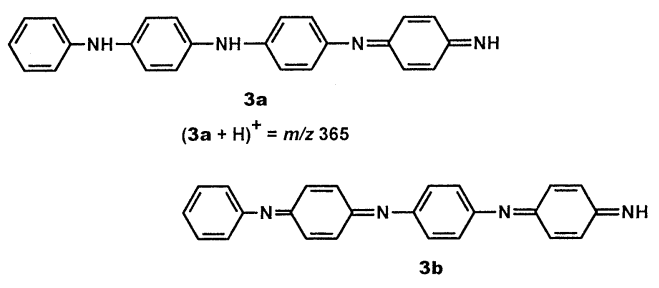

$(3 \mathbf{b}+\mathrm{H})^{+}=m / z 363$
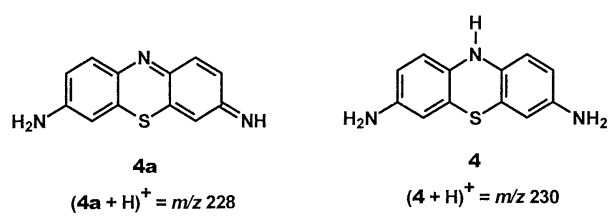

Structures

protonated molecule of the analyte, $(\mathbf{1}+\mathrm{H})^{+}$. There are also low abundance peaks at $\mathrm{m} / \mathrm{z} 183$ and 184. The former corresponds in mass to the protonated molecule of the oxidized analyte $\mathrm{N}$-phenyl-1,4-phenylenediimine, $(\mathbf{1} \mathbf{a}+\mathrm{H})^{+}$. The peak at $m / z 184$ may be either the radical cation $(\mathbf{1})^{+\cdot}$ or the protonated hydrolysis product $(\mathbf{1 b}+\mathbf{H})^{+}$. The origin of these lesser abundant oxidized species may be two-fold. First, $\mathrm{N}$-phenyl-1,4phenylenediamine is relatively easy to oxidize and with aging on the bench, is converted to $\mathbf{1 a}$, which can subsequently hydrolyze. Second, a small amount of the analyte may be oxidized in the ES emitter [to either 1a or $(\mathbf{1})^{+\cdot}$ ] by means of the electrochemical process inherent to the technique. However, at a flow rate of 50 $\mu \mathrm{L} / \mathrm{min}$, oxidation by that means should be minimal $[17,26]$.

The ions observed and their relative abundances in the APCI and APPI spectra of $\mathbf{1}$ were essentially identical and were very similar to those observed in the ES mass spectrum. One possibly important difference was the absence of the peak at $m / z 184$ in the APCI and APPI spectra. This absence points to the fact that radical cations (essentially half-oxidized $\mathbf{1}$ ) originally present in solution may not be observed in the gas phase with these ionization methods. Alternatively, the species that gave rise to this peak might have been formed as a result of the ES process and therefore was not present in the system. One would have expected to see the protonated molecule of the hydrolysis product $\mathbf{1 b}$ if it was present in solution.

Also shown in Figure 2 is the molecular ion region of the ES (Figure 2d), APCI (Figure 2e) and APPI (Figure 2f) mass spectra of a $\mathrm{pH} 4$ aqueous methanol solution of $\mathrm{N}$-phenyl-1,4-phenylenediimine, 1a. By means of the on-line electrochemical cell, the N-phenyl-1,4-phenylenediamine, 1, in the solution used to acquire the spectra shown in Figure 1 was near quantitatively oxidized to $N$-phenyl-1,4-phenylenediimine, 1a, prior to entering the ion source. As a result, the major peak in the ES mass spectrum (Figure 2d) was observed at $\mathrm{m} / \mathrm{z}$ 183 which corresponds to $(\mathbf{1 a}+\mathbf{H})^{+}$. A lower abundance of the radical cation (or protonated hydrolysis product) present at $\mathrm{m} / \mathrm{z} 184$ as well as the original reduced species at $\mathrm{m} / \mathrm{z} 185,(1+\mathrm{H})^{+}$, were also observed. In contrast to the ES mass spectrum, both the APCI (Figure 2e) and APPI (Figure 2f) mass spectra of this solution have as their base peak the reduced form of the analyte at $\mathrm{m} / \mathrm{z} 185$. Note also that the radical cation at $m / z 184$ was not observed in either the APCI or APPI spectra.

The data in Figure 2 illustrated that when the reduced form of the analyte was present in solution (i.e., 1), the ions observed in the ES, APCI, and APPI mass spectra were quite similar and were reflective of the analyte redox state originally present in the solution. However, when the oxidized forms of the analyte were present [i.e., $\mathbf{1 a}$ or $(\mathbf{1})^{+*}$, neither the APCI or APPI mass spectra were reflective of the true distribution of the analyte redox state in the solution. At some point in both the APCI and APPI process, a significant fraction of the oxidized forms of the analyte were effectively reduced, neutralizing ions originally present and/or adding mass to the molecules. Tandem mass spectrometry product ion spectra of the ions at $\mathrm{m} / \mathrm{z} 185 \mathrm{ob}-$ served in the spectra in Figures $2 b$ and $2 e$ were indistinguishable, strongly supporting the supposition that 1a was converted to 1, rather than to another species of the same mass, but different structure. Thus, the reduction process in the ion source forms the same species that would be formed by electrochemical reduction of 1a [17]. The same observations were made when the spectra were recorded from aqueous methanol at $\mathrm{pH} 7$.

Believing that the reduction process observed for the aniline $n$-mers and compound 1a might be related to the 1,4-phenylenediimine structure common to both, we also investigated the thiazine dye thionin, $4 a$, which contains the same substructure. This compound is also an important starting material used in the electrochemical formation of conductive polymers [29]. Indeed, we found that $4 \mathrm{a}$ was reduced to 4 . Importantly, for both this molecule and $\mathbf{1}$, the heated nebulizer probe temperature was found to influence the extent of reduction. The ES mass spectrum of a $\mathrm{pH} 3$ aqueous methanol solution of $4 \mathbf{a}$ was acquired along with the APCI mass spectra at heated nebulizer probe temperatures of 500, 


\section{EC cell open circuit}
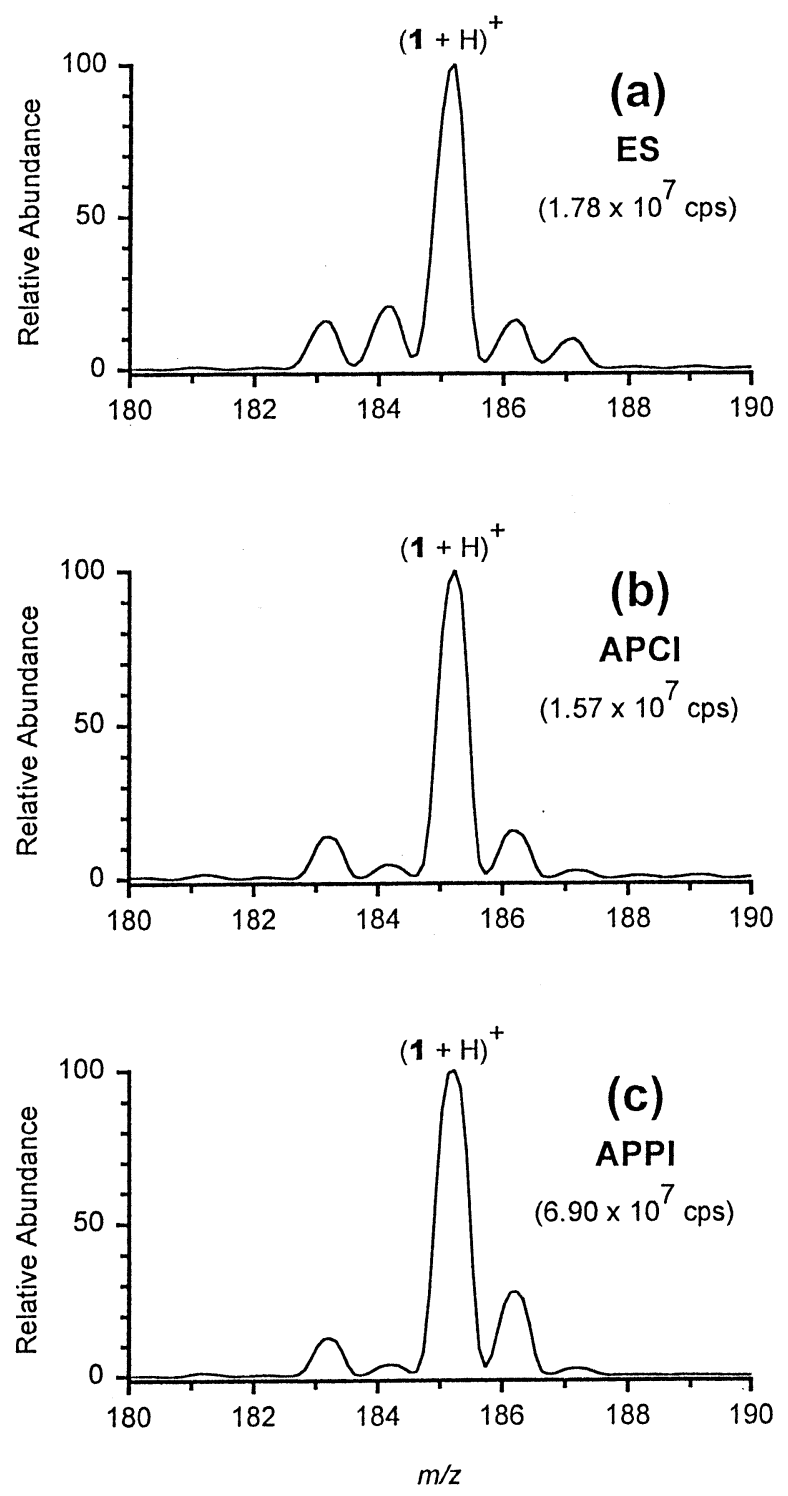

EC cell

$+1.0 \mathrm{~V}$
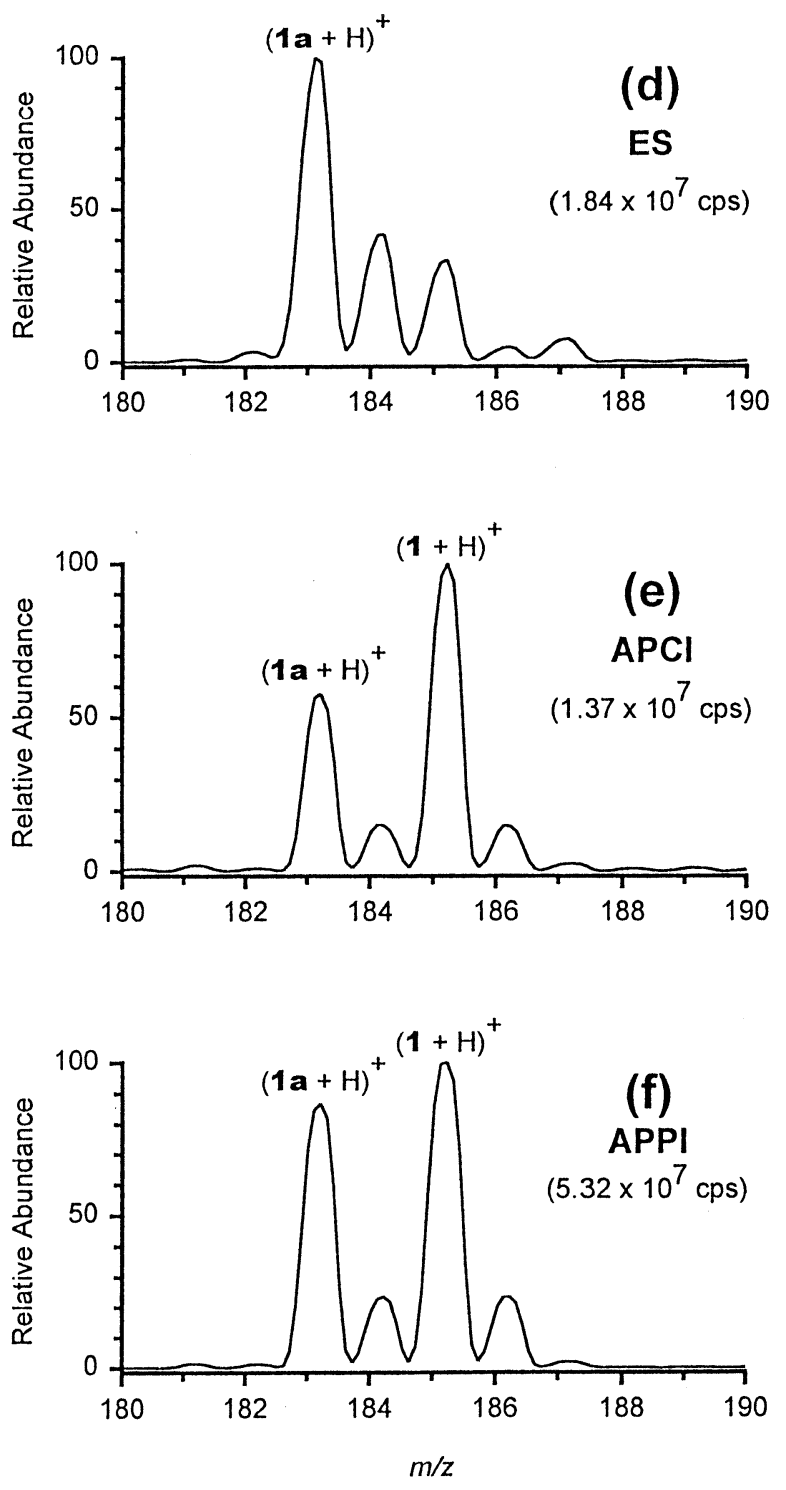

Figure 2. (a) ES, (b) APCI, and (c) APPI mass spectrum of $20 \mu \mathrm{M} \mathrm{N}$-phenyl-1,4-phenylenediamine, 1. (d) ES, (e) APCI, and (f) APPI mass spectrum of nominally $20 \mu \mathrm{M} N$-phenyl-1,4-phenylenediimine, 1a, produced on-line by electrochemical oxidation $(1.0 \mathrm{~V})$ of $N$-phenyl-1,4-phenylenediamine, $\mathbf{1}$. In all cases the solvent flow rate was $50 \mu \mathrm{L} / \mathrm{min}$, and the solvent was water/methanol $(50 / 50 \mathrm{vol} / \mathrm{vol})$ with $1 \%$ by volume formic acid ( $\mathrm{pH} 3)$. For both APCI and APPI the heated nebulizer temperature was $400^{\circ} \mathrm{C}$. APCI corona discharge current was $2 \mu \mathrm{A}$. APPI lamp current was $0.7 \mathrm{~mA}$ with an acetone dopant flow rate of $10 \mu \mathrm{L} / \mathrm{min}$.

400, and $300{ }^{\circ} \mathrm{C}$ (Figure 3). The ES mass spectrum showed exclusively the protonated molecule of this species, $(4 \mathbf{a}+\mathrm{H})^{+}$, at $\mathrm{m} / \mathrm{z} 228$ and the associated isotopomer ions (Figure 3a). In contrast, the APCI spectra show peaks owing to both the initial oxidized molecule $(4 \mathbf{a}+\mathrm{H})^{+}$at $m / z 228$ and the reduced species, $(4+\mathrm{H})^{+}$, at $m / z 230$. Furthermore, the abundance of the oxidized form relative to the reduced form of the analyte decreased as the probe temperature decreased (oxidized:reduced $=90 \%: 100 \%$ at $500{ }^{\circ} \mathrm{C}, 85 \%: 100 \%$ at $400{ }^{\circ} \mathrm{C}$, and $55 \%: 100 \%$ at $300{ }^{\circ} \mathrm{C}$, respectively, Figures
$3 \mathrm{~b}, 3 \mathrm{c}$ and $3 \mathrm{~d}$ ). The same trend was observed with a $\mathrm{pH}$ 3, 100\% aqueous solvent system. At the higher probe temperatures, the extent of reduction was in fact slightly more than that observed with the mixed water/ methanol solvent.

The increasing extent of reduction with decreasing probe temperature indicated that the reductions were probably not thermally induced [30]. Rather, this inverse relationship pointed to reduction via a surface process within the heated nebulizer probe. As the probe temperature decreases, the time the analyte molecules 

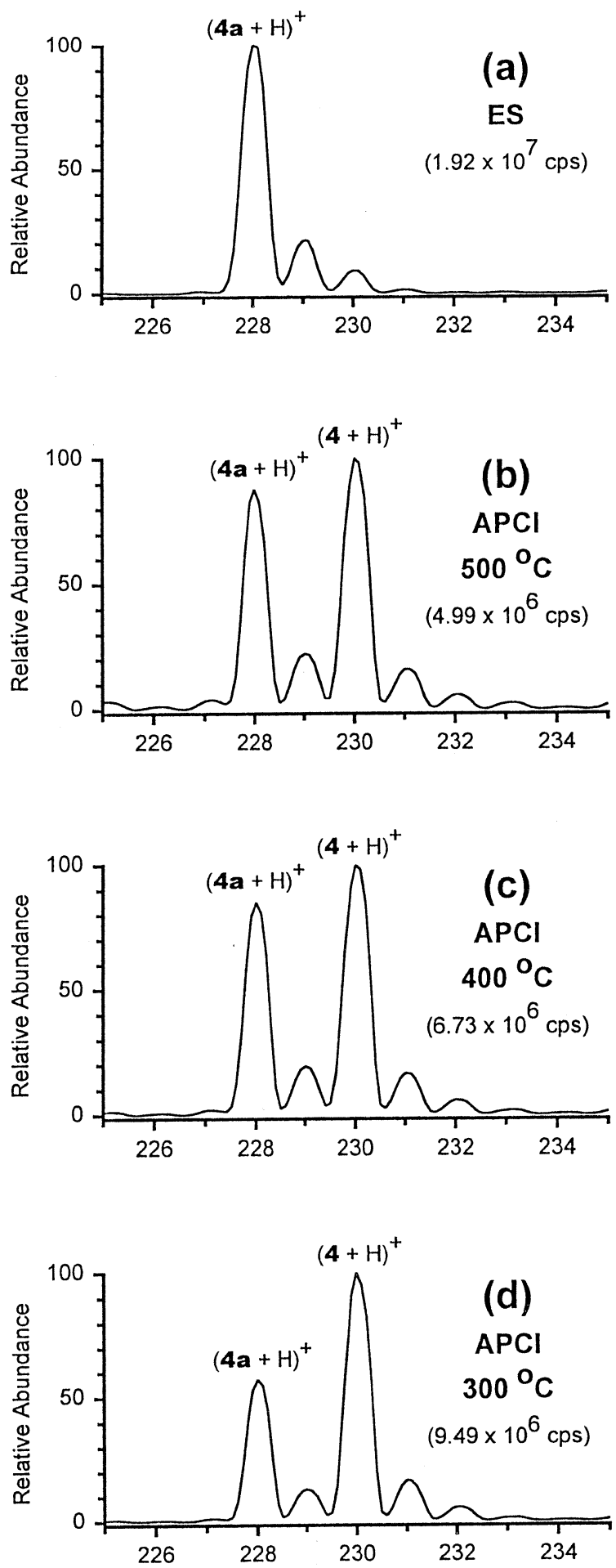

Figure 3. (a) ES mass spectrum and (b, c, and d) APCI mass spectra of $20 \mu \mathrm{M}$ thionin, 4 (water/methanol, 50/50 vol/vol, $1 \%$ formic acid, $\mathrm{pH}$ 3). APCI spectra were obtained at heated nebulizer probe temperatures of (b) $500{ }^{\circ} \mathrm{C}$, (c) $400{ }^{\circ} \mathrm{C}$, and (d) $300{ }^{\circ} \mathrm{C}$. Solvent flow rate was $50 \mu \mathrm{L} / \mathrm{min}$. APCI corona discharge current was $2 \mu \mathrm{A}$.

spend on the inner surfaces of the heated probe might be expected to increase. As more time is spent on the surface, the extent or efficiency of the analyte reduction might also be expected to increase. Consistent with this supposition, we found that the cleanliness of the quartz liner within the heated probe influenced the extent of the reduction under any given set of conditions. With a previously used, but freshly cleaned quartz tube liner in the heated nebulizer probe, the extent of the reduction of $4 \mathbf{a}$ was less $\left[(4 \mathbf{a}+\mathrm{H})^{+}:(\mathbf{4}+\mathrm{H})^{+}=100 \%: 60 \%\right.$ ] than when a dirty heated quartz liner was used $\left[(4 \mathbf{a}+\mathrm{H})^{+}\right.$: $\left.(4+\mathrm{H})^{+}=55 \%: 100 \%\right]$. The latter condition was that used to acquire all the data presented in this paper other than that taken with the freshly cleaned tube just referred to above. The greater extent of reduction when using a dirty probe liner suggests that residue on the liner from the analysis of previous samples promotes the reduction process. A cold and dirty source have previously been implicated as important factors in the surface-assisted reduction of analytes in a CI plasma source [3]. The exact nature of the surface character responsible for the reduction observed here (or in the case of CI for that matter [3]) remains to be determined.

Surface phenomena were important in the observed reduction of the analytes studied, but reactive species in the ionization plasma also were necessary. No major change in the extent of reduction of $4 \mathbf{a}$ was observed when the corona discharge current was varied from 1 to $5 \mu \mathrm{A}$ at a constant probe temperature. However, if the discharge current was turned off, signal for the oxidized analyte exclusively, albeit at very low abundance (ca. 3000 times lower than with the discharge current on), was observed. This observation was independent of probe temperature from 500 to $300{ }^{\circ} \mathrm{C}$. If the analyte was injected into the system with the discharge current off and the probe temperature low $\left(200^{\circ} \mathrm{C}\right)$, some analyte accumulated on the inner probe surface. This material could subsequently be driven off into the gas-phase by rapidly heating the probe to $500{ }^{\circ} \mathrm{C}$. If the discharge current remained off during this desorption process, only the oxidized species was observed in the spectrum. However, if the discharge current was turned on simultaneously with the beginning of the thermal ramp, the reduced form was also observed. Thus, the reduction reaction is associated with the analyte being on the surface, but it only occurs when the corona discharge plasma is operational.

One can speculate that the reactive species in these reductions are hydrogen radicals. These species have been implicated in reductions in other plasma ionization sources $[3,30]$. While we can offer no direct proof for this postulate, we did find that the percentage of water or other protic species in the solvent system influenced the extent of the reduction. All previous data shown or discussed was acquired using a 50/50 (vol/vol) methanol/water or $100 \%$ aqueous system at $\mathrm{pH} \mathrm{3,4}$, or 7. In these common APCI/APPI solvent systems $[2,8]$, the reductions were relatively efficient, particularly at lower heated nebulizer probe temperatures. When analyzed using 90/10 (vol/vol) acetonitrile/water, reduction of $\mathbf{4 a}$ was essentially eliminated (Figure $4 a$ ). When the percentage of water was increased to 50/50 (vol/vol) (Figure $4 \mathrm{~b}$ ) and then 

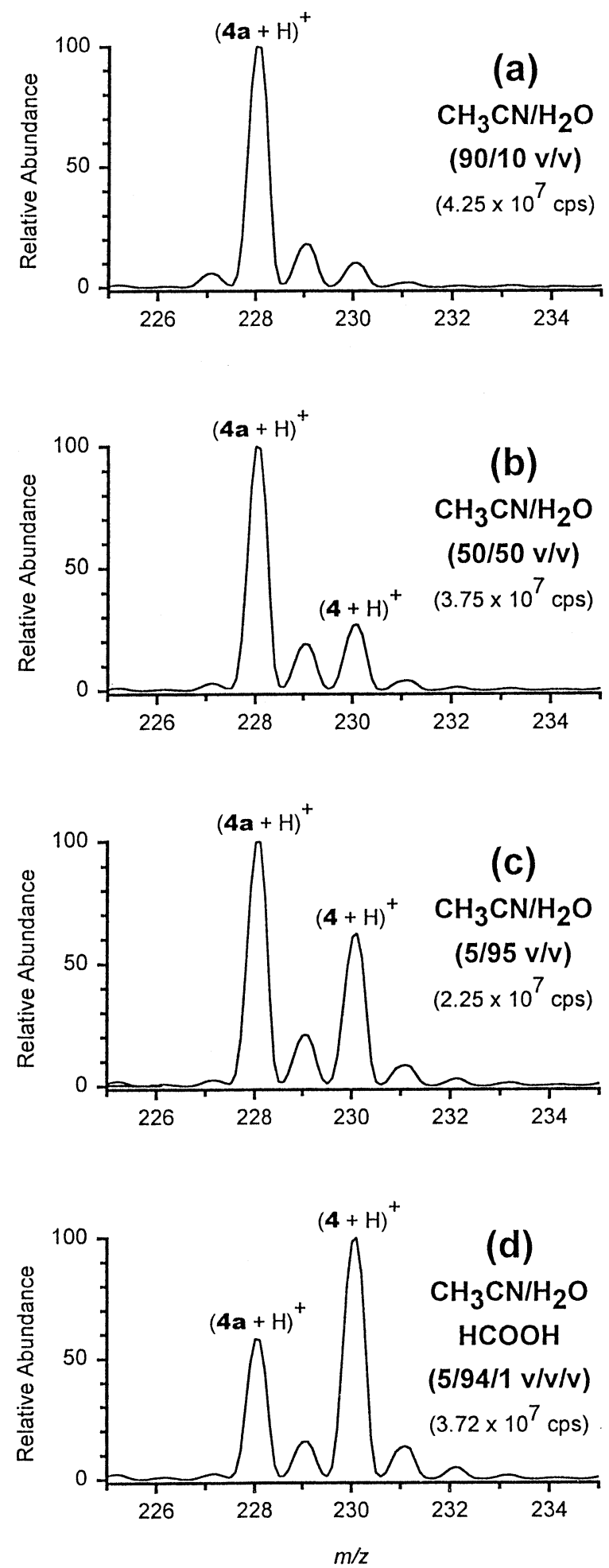

Figure 4. APCI mass spectra of $20 \mu \mathrm{M}$ thionin, 4 prepared in different aqueous acetonitrile solutions. (a) 90/10 (vol/vol) acetonitrile/water, (b) 50/50 (vol/vol) acetonitrile/water, (c) 5/95 (vol/vol) acetonitrile/water, and (d) 5/94/1 (vol/vol/vol) acetonitrile/water/formic acid. Heated nebulizer probe temperature was $500{ }^{\circ} \mathrm{C}$, the solvent flow rate was $50 \mu \mathrm{L} / \mathrm{min}$, and the corona discharge current was $5 \mu \mathrm{A}$.

5/95 (vol/vol) acetonitrile/water (Figure 4c), the extent of reduction observed progressively increased.
When formic acid was added to 5/95 (vol/vol) acetonitrile/water, the abundance of the reduced species $(4+\mathrm{H})^{+}$was of greater abundance than that of the originally introduced oxidized species (Figure 4d). In fact, this data resembled that obtained with 4a using a water/methanol $(50 / 50 \mathrm{vol} / \mathrm{vol})$ solution. The data in Figure 4 implicate the need for a protic solvent to induce the reduction process, a result similar to that noted by Karancsi and Slégel [1]. The presence of a protic solvent in the discharge plasma may facilitate the formation of hydrogen radicals, which in a surface-assisted process, reduce the analytes.

The aniline oligomers and compounds $1 \mathbf{a}$ and $4 \mathbf{a}$ were reduced in APCI (and APPI) when analyzed in aqueous methanol and aqueous ( $\geq 50 \% \mathrm{vol} / \mathrm{vol}$ ) acetonitrile. For each of these compounds, the reduction appeared to be a surface-enhanced process that involved reactive species produced from protic solvents (possibly hydrogen radicals) in the ionization plasma. Similar mechanisms have been put forward to explain certain reductions observed in low pressure CI plasmas $[3,30]$. The reduction of nitro aromatics in APCI reported by Karancsi and Slégel [1] was also dependent on the presence of protic solvents. However, that process was not found to be temperature dependant, and therefore, may in fact be a different, gas-phase reduction process.

\section{Conclusions}

The data presented here show that a surface-assisted reduction process, most likely involving hydrogen radicals formed from protic solvents in the atmospheric pressure ionization plasma, may be operational in both APCI and APPI. The reduction process was enhanced when using water, aqueous methanol, or an acidic solution as a solvent, when using low heated nebulizer probe temperatures $\left(\leq 400^{\circ} \mathrm{C}\right)$, and when using a dirty, heated nebulizer probe liner. Conversely, reduction could be completely eliminated or minimized through the use of nonprotic solvents (acetonitrile). High nebulizer probe temperatures $\left(500{ }^{\circ} \mathrm{C}\right)$ and a clean nebulizer probe helped to limit the extent of reduction if protic solvents were used.

The proposed reduction mechanism is comparable to that mechanism put forward for reduction of similar analytes in other ion sources in which there are reactive plasmas $[3-7,30]$. On the basis of the current results, it is suspected that compounds with the 1,4-phenylenediimine, thiazine, or related substructures might be prone to this surface-assisted reduction process. However, more work needs to be done to predict the generality of the process. The APCI and APPI reduction of the analytes shown here can be avoided by appropriate solvent choices. This presents a means to avoid incorrect mass assignments or quantitative errors in routine analytical investigations that might be caused by the occurrence of analyte reduction. However, in our work this solvent criteria limits the general utility of 
either ionization source for EC/MS experiments. Furthermore, radical cations, which are important intermediates and products of electrochemical reactions, were not observable with either ion source.

On the basis of our results, one might also speculate the possibility of similar reduction processes in other liquid introduction plasma ionization sources, including TS [6] and PB [7]. As such, these ion sources too should be used with caution for EC/MS experiments. Similar reduction processes in TS to those we observed here in APCI and APPI might in fact explain the EC/TS-MS results of Stassen and Hambitzer [31] in the study of aniline electropolymerization (water/ $0.1 \mathrm{M}$ sulfuric acid). Upon electrochemical oxidation of aniline, they observed in the TS mass spectrum the protonated reduced dimer, $(\mathbf{1}+\mathrm{H})^{+}$, at $m / z$ 185. At a much lower abundance, they observed the reduced form of the trimer, $(3+\mathrm{H})^{+}$, at $m / z 276$. No oxidized oligomers were observed. Our EC/ES-MS results in Figure 1a are consistent with the known electrochemistry of this polymerization showing that the oxidized, not the reduced, redox states of the dimer and trimer are formed electrochemically [17]. On the other hand, our EC/APCI-MS results in Figure 1b show a trend toward dominance of the reduced oligomers in the mass spectrum. One might therefore predict that the reduction of these oxidized oligomers in TS, under the operational conditions used by Stassen and Hambitzer [31], may be even more efficient than we observe in APCI (or APPI), leading to the observation of only the fully reduced oligomers in the gas-phase.

\section{Acknowledgments}

VK acknowledges support through an appointment to the Oak Ridge National Laboratory (ORNL) Postdoctoral Research Associates Program administered jointly by the Oak Ridge Institute for Science and Education and ORNL. APCI-, APPI-, and ES-MS instrumentation was provided through a Cooperative Research and Development Agreement with SCIEX (CRADA No. ORNL96-0458). This work was supported by the Division of Chemical Sciences, Geosciences, and Biosciences, Office of Basic Energy Sciences, United States Department of Energy under Contract DE-AC0500OR22725 with ORNL, managed and operated by UT-Battelle, LLC.

\section{References}

1. Karancsi, T.; Slegel, P. Reliable Molecular Mass Determination of Aromatic Nitro Compounds: Elimination of Gas-Phase Reduction Occurring During Atmospheric Pressure Chemical Ionization. J. Mass Spectrom. 1999, 34, 975-977.

2. Carroll, D. L.; Dzidic, I.; Horning, E. C.; Stillwell, R. N. Atmospheric Pressure Ionization Mass Spectrometry. Applied Spectrom. Rev. 1981, 17, 337-406.
3. Budzikiewicz, H. Reactions Between Substrate Molecules and Chemical Ionization Reagent Gas Prior to Ionization. Org. Mass Spectrom. 1988, 23, 561-565.

4. McEwen, C. N.; Layton, S. F.; Taylor, S. K. Field Desorption and Electron Impact Mass Spectra of Ionic Dyes. Anal. Chem. 1977, 49, 922-926.

5. Gale, P. J.; Bentz, B. L.; Chait, B. T.; Field, F. H.; Cotter, R. J. Reduction in Liquid Secondary Ion Mass Spectrometry. Comparison of the Fission Fragment and Liquid Secondary Ion Mass Spectra of Organic Dyestuffs. Anal. Chem. 1986, 58, 1070-1076.

6. Ballard, J. M.; Betwoski, L. D. Thermospray Ionization and Tandem Mass Spectrometry of Dyes. Org. Mass Spectrom. 1986, $21,575-588$.

7. Turnipseed, S. B.; Roybal, J. E.; Rupp, H. S.; Hurlbut, J. A.; Long, A. R. Particle Beam Liquid Chromatography-Mass Spectrometry of Triphenylmethane Dyes: Application to Confirmation of Malachite Green in Incurred Catfish Tissue. J. Chromatogr. B 1995, 670, 55-62.

8. Robb, D. B.; Covey, T. R.; Bruins, A. P. Atmospheric Pressure Photoionization: An Ionization Method for Liquid Chromatography-Mass Spectrometry. Anal. Chem. 2000, 72, 3653-3659.

9. Volk, K. J.; Yost, R. A.; Brajter-Toth, A. Electrochemistry On-Line with Mass Spectrometry: Insight into Biological Redox Reactions. Anal. Chem. 1992, 64, 21A-33A.

10. Diehl, G.; Liesener, A.; Karst, U. Liquid Chromatography with Post-Column Electrochemical Treatment and Mass Spectrometric Detection of Non-Polar Compounds. Analyst 2001, 126, 288-290.

11. Johnson, K. A.; Shira, B. A.; Anderson, J. L.; Amster, I. J. Chemical and On-Line Electrochemical Reduction of Metalloproteins with High Resolution Electrospray Ionization Mass Spectrometry Detection. Anal. Chem. 2001, 73, 803-808.

12. Kertesz, V.; Van Berkel, G. J. Electropolymerization of Methylene Blue Investigated Using On-Line Electrochemistry/ Electrospray Mass Spectrometry. Electroanalysis, in press.

13. Deng, H.; Van Berkel, G. J.; Takano, H.; Gazda, D.; Porter, M. D. Electrochemically-Modulated Liquid Chromatography Coupled On-line with Electrospray Mass Spectrometry. Anal. Chem. 2000, 72, 2641-2647.

14. Jurva, U.; Wikstrom, H. V.; Bruins, A. P. In Vitro Mimicry of Metabolic Oxidation Reactions by Electrochemistry/Mass Spectrometry. Rapid Commun. Mass Spectrom. 2000, 14, 529-533.

15. Pretty, J. R.; Deng, H.; Goeringer, D. E.; Van Berkel, G. J. Electrochemically-Modulated Preconcentration and Matrix Elimination for Organic Analytes Coupled On-Line with Electrospray Mass Spectrometry. Anal. Chem. 2000, 72, 2066-2074.

16. Arakawa, R.; Abura, T.; Fukuo, T.; Horiguchi, H.; Matsubayashi, G. Analysis of Electrolysis Reactions of Metal Complexes Using On-Line Electrospray Ionization Mass Spectrometry with a Compact Electrolysis Flow-Through Cell. Bull. Chem. Soc. Jpn. 1999, 72, 1519-1523.

17. Deng, H.; Van Berkel, G. J. Electrochemical Polymerization of Aniline Investigated Using On-Line Electrochemistry/Electrospray Mass Spectrometry. Anal. Chem. 1999, 71, 4284-4293.

18. Deng, H.; Van Berkel, G. J. A Thin-Layer Flow Cell Coupled On-Line with Electrospray-Mass Spectrometry for the Study of Biological Redox Reactions. Electroanalysis 1999, 11, 857-865.

19. Iwahashi, H. 3-Hydroxyanthralinic Acid-Derived Compounds Formed Through Electrochemical Oxidation. J. Chromatogr. B 1999, 237, 237-245.

20. Pretty, J. R.; Van Berkel, G. J. Electrochemical Sample Pretreatment Coupled On-Line with Electrospray Mass Spectrometry for Enhanced Elemental Analysis. Rapid Commun. Mass Spectrom. 1998, 12, 1644-1652.

21. Iwahashi, H.; Ishii, T. Detection of the Oxidative Products of 3-Hydroxykynurenine using High-Performance Liquid Chro- 
matography-Electrochemical Detection-Ultraviolet Absorption Detection-Electron Spin Resonance Spectrometry and High-Performance Liquid Chromatography-Electrochemical Detection-Ultraviolet Absorption Detection-Mass Spectrometry. J Chromatogr. A 1997, 773, 23-31.

22. Lu, W.; Xu, X.; Cole, R. B. On-Line Linear Sweep Voltammetry-Electrospray Mass Spectrometry. Anal. Chem. 1997, 69, $2478-2484$.

23. Xu, X.; Lu, W.; Cole, R. B. On-Line Probe for Fast Electrochemistry/Electrospray Mass Spectrometry. Investigation of Polycyclic Aromatic Hydrocarbons. Anal. Chem. 1997, 69, 24782484.

24. Bond, A. M.; Colton, R.; D'Agnostino, A.; Downard, A. J.; Traeger, J. C. A Role for Electrospray Mass Spectrometry in Electrochemical Studies. Anal. Chem. 1995, 67, 1691-1695.

25. Zhou, F.; Van Berkel, G. J. Electrochemistry Combined OnLine with Electrospray Mass Spectrometry. Anal. Chem. 1995, $67,3643-3649$.
26. Kertesz, V.; Van Berkel, G. J. Minimizing Analyte Electrolysis in an Electrospray Emitter. J. Mass Spectrom. 2001, 36, 204-210.

27. Lunte, S. M.; Lunte, C. E.; Kissinger, P. T. In Laboratory Techniques in Electroanalytical Chemistry; Kissinger, P. T.; Heineman, W. R., Eds.; Marcel Dekker: New York, 1996; Chap XXVII, pp 813-853.

28. Lemmon, T. L.; Westall, J. C.; Ingle, J. D., Jr. Development of Redox Sensors for Environmental Applications Based on Immobilized Redox Indicators. Anal. Chem. 1996, 68, 947-953.

29. Karyakin, A. A.; Karyakina, E. E.; Schmidt, H.-L. Electropolymerized Azines: A New Group of Electroactive Polymers. Electroanalysis 1999, 11, 149-155.

30. McEwen, C. N. Radicals in Analytical Mass Spectrometry. Mass Spectrom. Rev. 1986, 5, 521-547.

31. Stassen, I.; Hambitzer, G. Anodic Oxidation of Aniline and $\mathrm{N}$-Alkylanilines in Aqueous Sulfuric Acid Studied by Electrochemical Thermospray Mass Spectrometry. J. Electroanal. Chem. 1997, 440, 219-228. 